\title{
Article
}

\section{Self-evaluation of skills and performance level in youth elite soccer: Are positive self-evaluations always positive?}

Hofseth, Erik, Toering, Tynke, Jordet, Geir and Ivarsson, Andreas Available at https://clok.uclan.ac.uk/25798/

Hofseth, Erik, Toering, Tynke orcid iconORCID: 0000-0003-2411-2755, Jordet, Geir and Ivarsson, Andreas (2017) Self-evaluation of skills and performance level in youth elite soccer: Are positive self-evaluations always positive? Sport, Exercise, and Performance Psychology, 6 (4). pp. 370-383. ISSN 21573905

It is advisable to refer to the publisher's version if you intend to cite from the work. http://dx.doi.org/10.1037/spy0000094

For more information about UCLan's research in this area go to http://www.uclan.ac.uk/researchgroups/ and search for < name of research Group>.

For information about Research generally at UCLan please go to http://www.uclan.ac.uk/research/

All outputs in CLoK are protected by Intellectual Property Rights law, including Copyright law. Copyright, IPR and Moral Rights for the works on this site are retained by the individual authors and/or other copyright owners. Terms and conditions for use of this material are defined in the policies page.

\section{CLoK}

Central Lancashire online Knowledge www.clok.uclan.ac.uk

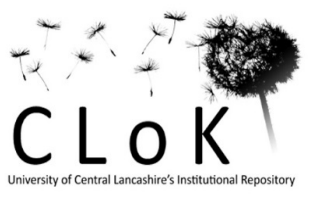


Project Determinants for overuse injury in Athletics: from the identification of risk patterns to the implementation of a preventive program in a real context View project 
1 Self-Evaluation of Skills and Performance Level in Youth Elite Soccer: Are

2 Positive Self-Evaluations Always Positive?

3

4

5

6

7

8

This study compared youth elite soccer players' and their coaches' evaluations of players' skill level, and examined how this comparison was related to players' future performance level concerning national team experience. Based on the notions of the self-serving bias, it was predicted that players who overestimated their skill level relative to their coaches' judgment, would be characterized by a high performance level in the past and a relative low future performance level; due to relatively high levels of performance anxiety and a frequent use of self-protection strategies. Results showed that the players $\left(N=267, M_{\text {age }}=17.6, S D=1.1\right)$, in reference to their coach, tended to overestimate their skills. This tendency was negatively related to players' future performance level. Specifically, when controlling for age, past performance level and current performance level, a multinomial regression analysis $\left.\left(\mathrm{X}^{2} 18, \mathrm{~N}=238\right)=76.95, \mathrm{p}<.01\right)$ revealed that the players who overestimated their skills to the largest extent (compared to players that underestimated their skills), were less likely to produce a high performance level in the future $(\mathrm{OR}=.71,95 \% \mathrm{CI}=.54$ 18 .94). It seems that unrealistically positive self-evaluations can have negative effects in terms of performance development, but not through the mechanism of the selfserving bias, as measured in the current study. Nevertheless, it may be important for players to have a realistic view on their skill-level in order to progress and reach their potential. 
The tendency to overestimate one's skills is a widespread human psychological phenomenon (Johnson \& Levin, 2009). In elite sport, it has been argued that realistic and accurate self-evaluations characterize those athletes who reach a performance level of excellence (MacNamare, 2011). In support of this, experimental research has demonstrated that the criteria for success is progressively linked to a realistic and accurate evaluation of one's task-specific skills in parallel to increased level of difficulty (Johnson \& Fowler, 2011). The selection process in most youth elite soccer academies and talent development systems resembles the structure of a pyramid; only the most skilful players are selected to progress from one age level to the next (Mills, Butt, Maynard, \& Harwood, 2012). In other words, the trajectory of difficulty, with respect to successfully transferring from one level to the next, increases with age in the context of youth elite soccer. This implies that an accurate selfestimate of skills might be of importance for ambitious young soccer players, if they are to excel and ultimately reach the top of the pyramid and become professional players (Toering, 2011). However, research has shown that many youth soccer players overestimate their skills, and those who do so are more likely to get injured than other players (Kantos, 2004). Further, we do not know through which mechanisms players may come to overestimate their skills, nor how the accuracy of their evaluations are related to their future performance level. In the current study we therefore explored the relationship between self-evaluated skills and future performance level in youth elite soccer players.

Sport psychology literature claims that positive evaluations of one's skills and abilities are one of the most facilitating psychological attributes affecting athletes' performance (Beaumont, Maynard, \& Butt, 2015; Hays, Thomas, Maynard, \& Bawden, 2009; Vealey, Hayashi, Garner-Holman, \& Giacobbi, 1998). Research on the role of self-evaluations of skills in sport performance has mainly been conducted in light of self-efficacy theory 
1 (Bandura, 1997) and the sport confidence model (Vealey et al., 1998). Self-efficacy refers to

2 "beliefs in one's capabilities to organize and execute the course of action required to produce

3 given attainments" (Bandura, 1997, p. 3). Whereas sport confidence refers to the degree of

4 certainty in one's ability to be successful in a given sport context (Vealey et al., 1998). In both

5 these concepts, positive evaluation of one's skills constitutes an implicit factor (Feltz, Short, \&

6 Sullivan, 2007). Therefore, previous research using these concepts and their theoretical

notions may shed light on the relationship between self-evaluated skills and performance level in youth elite soccer players.

Both self-efficacy theory and the sport-confidence model postulate that there is a positive reciprocal relation between self-evaluations and performance, thus suggesting that a positive interaction between these factors promotes performance development in athletes. Nevertheless, Vancouver and colleagues (Vancouver, Thompson, \& Williams, 2001) argued that self-efficacy may have a negative effect on performance. Accordingly, several studies have demonstrated that self-efficacy can have a negative relationship with subsequent performance on cognitive and motor tasks (Beattie, Fakehy, \& Woodman, 2014, 2016; Beattie, Lief, Adamoulas, \& Oliver, 2011; Halper \& Vancouver, 2016; Vancouver \& Kendall, 2006; Vancouver, Thompson, Tischner, \& Putka, 2002; Vancouver, Thompson, \& Williams, 2001; Woodman, Akehurst, Hardy, \& Beattie, 2010). Furthermore, in a recent meta-analysis encompassing studies scrutinizing the relationship between self-efficacy and performance, across disciplines, the researchers summarized their findings by stating that self-efficacy to a larger extent seems to be a product of past performance, rather than self-efficacy being the driving force affecting future performance (Sitzmann \& Yeo, 2013). The same pattern of results is visible in some sport specific studies investigating the relationship between past success and future performance. For example, baseball players who perform exceptionally well during their first year as professional players are more likely than other players to 
experience a performance drop during their second year as professional players (Taylor \& Cuave, 1994). Likewise, soccer players having a history of international merits have been found to be more likely than their lesser successful counterparts to choke under pressure (Jordet, 2009). One may argue that, although self-evaluations were not measured in these basketball and soccer players, increased self-efficacy or confidence may have played a mediating role and account for the negative relationship between players past and current performance level. In sum, there seems to be sufficient evidence to challenge the positive reciprocal relationship between positive self-evaluations and performance across situations and populations, suggested by theory and early research (e.g., for review see Bandura, 1997; Feltz, Short, \& Sullivan, 2007). Rather, research seems to suggest that in some cases, positive self-evaluations may negatively influence performance (e.g., Woodman et al., 2010).

Interestingly, the negative effect has been linked to those participants who evaluate themselves higher than their objective performance warrants (Moores \& Chang, 2009). Further, Beattie et al. (2011) found that participants on a golf putting task consistently overestimated their performance capabilities, even though they knew they were performing below their estimates. This positive self-bias may in part explain the negative relationship between self-efficacy and performance.

The reason why people may come to overestimates themselves is the tendency to internalize successes and externalize shortcomings, which is called the self-serving bias (Heider, 1958). This process is driven by the desire to experience positive emotions and avoid negative emotions (Baumeister, 1997; Campbell \& Sedikides, 1999). The self-serving bias tends to be amplified by negative self-relevant information concerning valued attributes. Specifically, when people face information that negatively challenges their self-views, they are likely to feel threatened and experience negative affect. In this uncomfortable state, people seem to be prone to make self-serving attributions and engage in self-serving behaviors -as 
means of escaping their distress (Baumeister, 1997; Campbell \& Sedikides, 1999). In this perspective, athletes may evaluate and maintain an overly positive view of their skills because they overemphasize their past successes (e.g., I succeeded because my skills are very good) and downplay their shortcomings. Drawing on these perspectives, Jordet (2010) argued that when athletes encounter a situation that negatively challenges their self-view, with respect to skills and performance, they are likely to experience competitive anxiety. As a means of coping with their anxiety, athletes are likely to employ counter-productive self-protective strategies to externalize their shortcomings, such as self-handicapping (Jordet, 2010). Selfhandicapping typically involves behaviors, or lack of behaviors, that compromise the quantity or quality of practice so potential display of poor skill level can be blamed on the circumstances rather than the self (Prapavessis, Grove, \& Eklund, 2004). In contrast to this mechanism, there is a considerable amount of evidence suggesting that ongoing performance development requires that shortcomings are confronted with deliberate efforts directed at improving them (Ericsson, Krampe, \& Tesch-Römer, 1993; Toering, 2011). During competition and training activities, athletes who overestimate themselves are likely to receive threatening feedback, which implies that they should lower their favorable self-view (Baumeister, 1997). Consequently, such feedback might onset the previously described selfserving self-protective mechanism - potentially inhibiting them from confronting and improving their skill level. In sum, we propose that past success may generate self-views that exceed athletes' actual skills, which in turn may constrain their future performance level (Beattie et al. 2011).

In the current study, youth elite players' and coaches' evaluations of players' skill level was compared, and related to players' past and future performance level. In addition, self-reported competitive anxiety, and self-reported use of self-protection strategies were taken into account. We predicted that players who overestimated their skill level relative to 
their coaches' judgment, would be characterized by a high performance level in the past and a relative low future performance level. Furthermore, we expected them to report a relatively high level of performance anxiety and a frequent use of self-protection strategies.

\section{Method}

\section{Participants}

The participants in the current study were all the soccer players $(N=338)$ from 16 to 21 years $(M=16.8, S D=1.8)$. All players played for a team within the 16 [COUNTRY BLINDED] Premier League clubs. All teams compete in regional leagues, which are organized in age specific levels. Players with a particularly high skill level in some cases played for a team a level above their corresponding age level, and even for the clubs first team. From the age 16years, most professional clubs recruit as skillful and promising players as possible with the aim of one day either using them as first team players or selling them to other professional clubs (Brown \& Potrac, 2009). Hence, this sample consisted of the most skillful and talented soccer players in [COUNTRY BLINDED], and thus also to a large extent constitutes the population of youth national team players in [COUNTRY BLINDED].

\section{Procedures}

After having obtained project and ethical approval from the [COUNTRY BLINDED] Data Protection Authority, participant clubs and teams were recruited during a national offseason coaching seminar for the 16 [COUNTRY BLINDED] Premier League clubs.

Participants received written information about the project and submitted written consent before participating; those under 16 years of age required parental consent. Data were collected using a set of questionnaires. The players filled in the questionnaires in group settings within their team, in or near their club facilities. This process was administered by 
1

2

two test leaders, following a standardized protocol assisted by the teams' staff. Data were collected on two occasions. First, players and coaches filled in an assessment of the players' skill level. Players also filled in self-report measures regarding their level of competitive anxiety and use of self-protective strategies. The second data collection took place two years after the first assessment. At this time, players' track record of national team games was obtained from the [COUNTRY BLINDED] national soccer association official database (REFERANCE BLINDED) (see Figure.1 for illustration).

\section{Measures}

Skill evaluation. Our measure of skill evaluation was based on the approach applied in other studies aiming at evaluating skills in sports with emergent skills (e.g., Felson, 1981; VanYperen, 2009; Van Yperen \& Duda, 1999). Specifically, we consulted with two professional soccer coaches experienced at coaching youth elite players from different cultural backgrounds, with the aim to disclose the most relevant soccer skills for soccer performance, across playing positions. Based on this consultation, an instrument asking an evaluator to rate a player's attacking skills, defending skills, mental skills, and physical skills was created. Each skill was presented as a single item underlined with a short description indicating more specifically what should be evaluated. For example, attacking skills were underlined by; ball control, passing/receiving, and decision-making. In the players' questionnaire, the instruction was rate their current skill level in reference to the age corresponding players within [COUNTRY BLINDED] using on a scale of 0 (lowest) to 10 (highest). In the coaches' questionnaire, the instruction was to rate the specific players level in reference to the age corresponding players within [COUNTRY BLINDED] using on a scale of 0 (lowest) to 10 (highest). 
2 Anxiety Scale-2 (SAS-2; Smith, Smoll, Cumming, \& Grossbard, 2006). The SAS-2 is a trait measure, including three dimensions of performance anxiety: somatic symptoms; worry symptoms, and; concentration disruption symptoms. Each dimension consists of five items that are rated on a 4-point scale, ranging from 1 (not at all) to 4 (very much). Each item is rated anchored in the stem: "Before or while I compete in sports ..." Example items reflecting the different anxiety dimensions are: "my body feels tense" (somatic), "I worry I will not play well" (worry), "it is hard for me to focus on what I am supposed to do" (concentration disruption). The reliability for all three factors was good in the current study (somatic: $\alpha=.77$, worry: $\alpha=.91$ concentration disruption $\alpha=.78$ ).

Self-protection strategies. We measured two types of self-protection strategies; selfhandicapping and sandbagging. Self-handicapping was measured using the soccer specific self-handicapping scale developed by Ommundsen, Roberts, Lemyre, and Abrahamsen (2007). This instrument consists of six items, distributed on one factor, asking about strategies that soccer players may use for self-handicapping. The items are introduced with this sentence in the heading: "Below are examples of things most soccer players do at one time or another. Please tell how true each of these is for you. One example of an item is, "Some players deliberately choose not to give their best effort in training so that if they don't do as well as they had hoped, they can say that is the reason.” Responses were indicated on 5-point scales, ranging from 1 (very much like me) to 5 (very much unlike me). The reliability for this scale was good in the current study $(\alpha=.86)$.

Sandbagging was measured using the behavioural sandbagging tendency factor of the Sandbagging Scale (Gibson \& Sachau, 2000; Sachau, Simmering, Adler \& Ryan, 2014). This factor consists of three items indicating a person's propensity to downplay his abilities. The items were introduced with the following sentence: "Below are examples of what soccer 
1 players think, feel, and do at one time or another. Please indicate how true each of these

2 statements is for you. One example of an item is, "I may understate my abilities to take some

3 of the pressure off".The items were introduced with the following sentence: "Below are examples of what soccer players think, feel, and do at one time or another." Responses were indicated on a scale ranging from 1 (disagree very much) to 6 (agree very much). The reliability for this scale was adequate in the current study $(\alpha=.79)$.

Performance level. Performance level was indicated by players' track record of international games representing [COUNTRY BLINDED]. Given the age range in the sample (16-21 years), all players had been eligible for playing international matches (U16, U17, U18, U19, U20, U21, U23, first team) for a year and a half (youngest players) prior to assessing their skill level, with the follow up assessment occurring two later. Given that only the best players within each age level are selected for international matches representing their country, it was assumed that number of national team games represented their performance level; the more matches the higher the performance level. Specifically, number of accumulated matches prior assessment of skill, indicated players' past performance level, while participation on last national team gathering (yes/no) indicated current performance level, and number of matches after assessment of skill, indicated players' future performance level (see Figure.1 for illustration).

\section{Data analysis}

Preliminary analysis. The first step in the analysis process was screening the data. During this process, 71 participants were removed from the sample because they either had incorrectly filled in their questionnaires $(n=15)$, or had not been ranked by their coach $(n=$ 56). Among the remaining 267 participants, 239 (89.5\%) participants had no missing values, whereas $28(10.5 \%)$ participants had one or more missing values. In players with missing 
1

2

values, Little's MCAR test suggested that values were completely missing at random, $X^{2}$ (504, $N=28)=425.38, p=.99$. Furthermore, a one-way ANOVA analysis showed that these two groups of players did not differ significantly from each other on any of the variables, and power estimates between these two groups on these variables was very small $(\phi<.01)$. Thus, missing values were not replaced.

Main analysis. A latent class analysis (LCA) was performed in order to identify subgroups within the population based on the players' and the coaches' ratings of the players' skills using the maximum likelihood estimator in Mplus 7.1 (Muthén \& Muthén, 1998-2012). More specifically, players were divided into different groups based on these two sources of skill evaluation. The LCA is a person-centered approach that is based on an underlying latent variable that determines and individual's class membership. In comparison to using traditional cluster analyses the LCA offers several advantages, such as allowing for more flexible model specification (Sterba \& Bauer, 2010). A sequence of nested models, starting with one class, was compared to examine if more complex models (i.e., a model containing one more class) fitted the data better than more parsimonious models. In the present study, models with one to four classes were tested to identify the optimal model. Different criteria were used to determinate the best model. First, the Bayesian Information Criterion (BIC; Henson, Reise, \& Kim, 2007) was inspected, with lower values indicating better model fit. Second, the bootstrap likelihood ratio test (BLRT; Nylund, Asparouhov, \& Muthén, 2007) was used to compare the fit of two competing models. A statistically significant test $(p<.05)$ indicate that the current model solution fits the data better than a model solution with one less class. Third, the entropy criterion was examined, which indicates how accurately the participants are classified into their respective profiles. Values closer to 1 indicates better accuracy (Berlin, Williams, \& Parra, 2014). Fourth, an expert evaluation was performed by the authors to select the solution that was most meaningful from a theoretical perspective. 
2 skill level within the different classes were calculated based on Cohen's d (1988). Finally, we (1) conducted a multinomial logistic regression analysis, predicting class adherence, based on players' past performance level, current performance level, future performance level, trait competitive anxiety factors (somatic symptoms, worry symptoms, concentration disruption), self-handicapping, and sandbagging tendencies. Due to the wide range of age in the sample, age was included as a covariate. Class number 3 was selected as the reference category - as this was the only class not characterized by players overestimating their skills in reference to their coach.

(10)

Concerning the LCA analysis, we tested three models based on the players' as well as coachers' ratings; one with two, three, and four classes, respectively. The model with three classes was decided as the best choice (entropy $=.76$, likelihood ratio test $p=.02$, Class one, $n$ $=77$; class two, $n=90$; class three, $n=100$ ). Each class showed unique features. Class one was characterized by low player and low coach ratings. In this class, players' ratings exceeded coaches' ratings moderately. Class two was characterized by high player ratings and moderate coach ratings, and players' ratings exceeded coaches' ratings strongly. Class three was characterized by an opposite pattern of class one and two; showing moderate player ratings and high coach ratings, where coaches' ratings exceeded players' rating, strongly. The ratings from both players and coaches, across and within classes, are displayed in Figure 2.

The multinomial logistic regression analysis yielded a significant overall model $\left[X^{2}\right.$ $(18, N=238)=76.95, p<.001]$, which explained $31 \%$ (Neqelkerke) of the variance in group adherence. However, only trait concentration disruption symptoms of anxiety $\left[X^{2}(2, N=238)\right.$ 
$1=7.86, p<.05]$, and future performance level $\left[X^{2}(2, N=238)=25.40, p<.001\right]$ made a

2 unique statistical contribution to the model. Specifically, in comparison to players in class

3 three, the players in class one reported a higher level of concentration disruption symptoms of

4 anxiety, by an odds ratio of $3.69(95 \% \mathrm{CI}=1.21-11.29)$. This implies that for each point a

5 player scored higher on trait concentration disruption symptoms of anxiety, his chance for

6 belonging to class one, in comparison to belonging to class three, increased by 3.69 times.

7 Players belonging to class two were distinguished from players belonging to class three also reporting a higher level of trait concentration disruption symptoms of anxiety, by an odds ratio of $3.84(95 \% \mathrm{CI}=1.23-12.02)$. Thus, for each point a player scored higher on trait concentration disruption symptoms of anxiety, his chance for belonging to class two, in comparison to belonging to class three, increased by 3.84 times. Furthermore, players belonging to class two were distinguished from players belonging to class three by being less likely to play international matches the next two years, indicated by an odds ratio of 0.71 $(95 \% \mathrm{CI}=0.54-0.94)$. Thus suggesting that for each international match players had played in the two forthcoming years, since the assessment of skills was obtained, their chance of belonging to class two decreased by approximately $29 \%$ in comparison to belonging to class three.

\section{Discussion}

In the current study, we compared youth elite soccer players' and coaches' evaluation of players' skill level, and examined the relation between this comparison and players' performance development. We hypothesized that past success, in terms of high performance level, may be related to players' overestimation of their skills in relation to their coach, and subsequently impair their performance development through a self-serving mechanism characterized by elevated levels of trait competitive anxiety and frequent use of self- 
protection strategies. Our exploratory analysis identified three subpopulations in the sample, where players in two subpopulations overestimated their skills compared to their coach, one moderately and the other strongly. In contrast, the players in the third subpopulation underestimated their skills compared to their coach, to a strong extent. The results showed that, in comparison to the players who underestimated their skills, the players that strongly overestimated their skills compared to the coach's judgment were more likely to exhibit a low performance level in the future, whereas both the players that overestimated their skills moderately and highly reported higher levels of trait competitive anxiety, in the form of concentration disruption. The results, however, also demonstrate that the use of selfprotection strategies did not discriminate between the groups, thus indicating that the negative relationship between overestimated skills and future performance level is not generated by a self-protective self-serving mechanism, as measured in the current study at least.

In an extensive review on the validity of self-evaluation of abilities and skills it was reported that people, compared to their supervisor, tend to overestimate their skills (Mabe \& West, 1982). This tendency has also been found in college football players in association with the ratings from their coach (Felson, 1981). The results of the current study are in line with these previous findings, as our results suggested that $63 \%$ of the players belonged to the classes that overestimated their skill level compared to their coach's evaluation. It thus seems as overestimating one's skills is a psychological phenomenon that is evident in youth elite soccer players.

Past sport psychology research clearly indicates that positive self-views are adaptive characteristics in athletes, because perceived ability, self-esteem, self-concept, selfconfidence, and self-efficacy typically have been positively related to desirable factors such as flow, effort, a preference for challenging tasks, well-being, enjoyment, persistence, and performance (e.g., Chase, 2001; Escarti \& Guzman, 1999; Koehn, 2013; Marsh \& Perry, 
2005; Reinboth \& Duda, 2004; Scanlan, Carpenter, Lobel, \& Simons, 1993). Nevertheless, the results of the current study showed that the players that evaluated their own skills highest, compared to their peers, were not the players that were associated with the highest skill level by their coach. Moreover, these same players did not play the most national team matches in the future either. As these players also were the ones that yielded the largest discrepancy to their coaches' estimate of their skills, our study indicates that positive self-views can have negative effects with respect to performance development - particularly if they become overly positive. This is in line with a body of research inspired by the work of Vancouver and colleagues (Vancouver et al., 2002; Vancouver et al., 2001). These studies have typically shown that the relationship between self-evaluations and performance is more complex than the unconditional positive reciprocal relationship predicted by self-efficacy theory and the sport-confidence model (e.g., Beattie et al., 2014, 2016; Beattie et al., 2011; Halper \& Vancouver, 2016; Woodman et al., 2010). In addition, these studies have adopted a withinperson approach of measuring self-evaluation and performance. As opposed to the frequently applied between-person approach (see Feltz, Sullivan, \& Short, 2007), increases or decreases in any factor are measured relative to the specific person's previous estimates, and not relative to the mean person's estimates. Consequently, a reason why there is a contrast in the research literature concerning the nature of the relationship between self-evaluation and performance is likely to be due to different use of methodology and measurement (Beattie et al., 2016). Furthermore, current research has also disclosed that there are several moderating factors in the relationship between self-evaluation and performance. For example, a recent study has shown that increasing practice time and making the learning condition more challenging on a golf putting task had a positive effect on the self-efficacy- performance relationship (Beattie et al., 2014). Furthermore, concrete versus abstract feedback has shown to have the same moderating effect on the self-efficacy-performance relationship (Beattie et al., 2016). Taken 
together these studies, including the current one, exemplify that the relationship between selfevaluations and performance is complex, both with respect to measurement and moderating factors, which means that it needs further exploration.

Unfortunately, the current study cannot account for the mechanism through which overestimated skills were associated with a relatively low future performance level, as the use of self-protection strategies was not related to performance. Although the results indicated that players who overestimated their skills moderately and highly, in comparison to players who underestimated their skills, reported higher levels of trait completion anxiety in the form of concentration disruption, both subpopulation associated with a high level of trait competitive anxiety were the players who was rated lowest by the coach. We therefore favor the explanation that trait competitive anxiety is linked to a low skill level rather than overestimated skills per see. In addition, the correlational analysis indicated that overestimation of skills was unrelated to any form of trait competitive anxiety. In this perspective, the results confirm previous research showing that competitive anxiety discriminates the very best athletes from the second best athletes (e.g., Jones, Hanton, \& Swain, 1994).

Experimental research has demonstrated that low skilled people tend to overestimate their skill and performance level, whereas highly skilled people tend to underestimate their skills and performance level (Kruger \& Dunning, 1999). One explanation that has been proposed is that, in complex and abstract tasks particularly, the skills required for recognizing incompetence to some extent are the same skills necessary for producing competence. For example, a soccer player needs to be aware of what the optimal choice and timing of a skill execution in a particular situation is, in order to both recognize a suboptimal action and produce the adequate action. A lowly skilled player may therefore execute a skill suboptimally, but believe he was relatively proficient, while a more skillful player may 
execute the same action in the same situation but believe he was relatively unsuccessful because he evaluates his performance to a higher standard. The tendency that top performers underestimate their skills, is a characteristic evident across domains (for an overview, see Dunning, 2005), and has been labeled "the burden of expertise" (Kruger \& Dunning, 1999). Interestingly, the results of the current study indicate that players who underestimated their skills relative to the coach's evaluation, in comparison to players that overestimated their skills relative to the coach's evaluation had a higher likelihood of producing a high performance level in the future. Additionally, the correlational analysis indicated that overestimated skills were more negatively associated to future performance level, than to past performance level. In sum, this implies that underestimated skills may be a characteristic of the top performers to come, and that "the burden of expertise" could explain the results of the current study to some extent.

Alternatively, some research has come to show that high self-evaluations, in the form of self-efficacy is associated with reduced effort and practice in various types of tasks (e.g., Vancouver \& Kendall, 2006; Wood \& Feltz, 2013). For example, when the relationship between self-efficacy and performance (grade) was examined in students over four exams, results showed that when students' self-efficacy increased by a grade, the time they used to study decreased significantly, followed by a reduced exam performance by a quarter of a grade (Vancouver \& Kendall, 2006). Such findings have typically been explained in the light of perceptual control theory. This theory predicts that motivation equals the discrepancy between current states and desired states (Powers, 1973), and, when information of current states is ambiguous, self-efficacy beliefs might function as a point of reference for one's current state (Powers, 1991). Thus, positive self-evaluations may be negatively related to performance, mediated by effort, because the need to invest maximum effort to reach one's goal is no longer perceived. The latter can be explained by a low discrepancy between current 
and desired state (Vancouver et al., 2001; Vancouver et al., 2002). If we try to translate these findings to the current study, we could speculate that players may reduce effort and quality in preparatory situations (e.g., training or preparation to match) as a result of complacency rather than self-protection. This also suggests that their biased self-evaluation may not be directly interrelated with their skill level and constrained by their skill level, but that they may use maladaptive sources of information as reference points in their goal-process. In other words, self-evaluated skill level might not be a functional point of reference - if the goal is to play as many national team games as possible.

A practical implication is that unrealistically positive self-evaluations of skills should be recalibrated towards being more realistic, as our findings indicated that those players that evaluated their skills highest, and higher than the coaches evaluated them, showed a reduced likelihood of playing national team games in the future (Moores \& Chang, 2009). Consequently, coaches should guide players to gain insight into the requirements of the level that players want to get to, which may help them direct their training efforts more effectively and produce a higher performance level. Related to this, it has been found that youth elite players that are given the opportunity to practice and play matches with players at a higher level, consider this a valuable learning experience, because it benchmarks their current performance and skill level in regards to the standard they need to attain in the future (Christensen, Laursen, \& Sørensen, 2011). In addition, given that it has been found that increased practice time and challenging learning conditions can have a positive moderating effect on the relationship between self-efficacy and performance (Beattie et al., 2014), we propose that realistic self-evaluations and insight into requirements for top performance, may be fostered in players by practicing with older and more skillful players. Furthermore, as concrete versus abstract feedback can have a positive influence on the self-efficacyperformance relationship (Beattie et al., 2016), coaches could stimulate players to critically 
self-reflect on their skill level by providing them concrete feedback, for example by using video feedback. We suggest that practitioners focus on controllable behavioral factors rather than uncontrollable personal factors when giving feedback. That is because the person then feels more flexible to adjust, and is more likely to adaptively cope with potential emotional distress following negative feedback (Tangney \& Dearing, 2002). Furthermore, several sport psychologist have suggested that athletes first should refine their skills in an environment that is perceived as socially and physically safe. Then, when the skill is sufficiently mastered, the athletes are better equipped to test themselves in a more socially and physically challenging environment (Hofseth, Pedersen, Toering, \& Jordet, in press; McGrath \& Elison, 2014).

Coaches should therefore only encourage transitions across age levels, if players have a good enough skill-level, and is mentally ready to thrive among older and very skillful players.

The current study is not without limitations. First, players and coaches may have interpreted the skill evaluation questionnaire differently as they have different experience and knowledge concerning soccer. This implies that we cannot exclude the possibility that the discrepancies between players' and coaches' evaluation of players' skill level to some extent reflects a response bias. Thus, we cannot with confidence claim that it is the coach or the player that over or underestimates the players' skill level, we can only relate them to each other. Second, because the players' coach, at their club, report players' status with respect to performance to the national team coach, players' track record of national team experience may be product of the coaches' assessment of the players, indicating that the discrepancy between the players and the coaches' skill assessment may be unrelated to players' national team experience. However, if this was the case, we would expect that the predictive analysis would demonstrate that players' past national team experience discriminated between the classes, which it did not. Third, previous research has also shown that adolescent players who evaluate their skill level very high, and those who overestimates themselves have an increased 
risk of injury (Kantos, 2009), which itself represents a threat against the reliability of the measure. Fourth and finally, the relative age affect has previously been found to be an influential factor in the selection process for adolescent national teams across countries (Helsen, Van Winckel, \& Williams, 2005). That is, players born during the first months of the year seem to be over- represented om youth national teams due to the fact that they have an advantage concerning growth and maturational factors, as they are relatively older than their peers born later the same year. This means that this is a factor is likely to influence players' record of national team games that the current study does not account for. In sum, there are many unanswered questions concerning the nature and moderating and mediating factors potentially influencing the relationship between self-evaluations and performance in soccer players. In the current study soccer skills was measured in a generic manner across playing positions. However, match analysis researcher clearly shows that the different playing positions in soccer each have unique demands with respect to skills (for review see, Sarmento, Marcelino, Anguera, Campanico, Matos, \& Leitão, 2014). Furthermore, as overestimation of skills has been linked to opportunism and risk taking (e.g., Johnson \& Fowler, 2011, Kantos, 2009), we speculate that in soccer players, playing positions and position specific skills might be potential moderating factors in the relationship between skill-evaluations and performance level. In strikers for example, a high estimate of own skills might be adaptive because they are typically close to the oppositions goal and far away from their own goal when they handle the ball. This means that they might have much to gain by attempting hazardous actions with low likelihood of success (e.g., scoring goal), than they have to lose if they are unsuccessful (e.g., low probability of providing the oppositions with scoring opportunities), compared to players in other positions.

The findings in the current study supports previous studies that has used a withinperson approach when measuring self-evaluation, showing that there can be a negative 
relationship between self-evaluation and subsequent performance and performance development in athletes (Beattie et al., 2014, 2016; Beattie et al., 2011; Halper \& Vancouver, 2016; Woodman et al., 2010). The sum of these studies imply that when researchers design and discuss the results of their studies, it is important that they keep in mind that a withinperson approach versus a between-person approach is likely to shed different light on the relationship between self-evaluations and performance.

\section{Conclusion}

The results indicated that overestimated skills compared to the coach's estimation were negatively related to soccer players' future performance level, while underestimated skills were positively related to players' future performance level. Based on previous research, we suggested that this finding may to some extent be explained by the "burden of expertise", meaning that the skills required for recognizing incompetence, among soccer players, may to some extent depend on their ability to produce competence. Alternatively, these results may be understood in the light of perceptual control theory (Powers, 1973); motivation is a product of the discrepancy between current and desired states. Thus, players who evaluates their skills very high may be less motivated to put forth effort in improving their skills in comparison to players who evaluates their skills lower, given that they have the same goals for their skill level, which may be reflected in players future performance level.

\section{Acknowledgments: [BLINDED]}


2 Bandura, A. (1997). Self-efficacy: The exercise of control. New York, NY: Freeman.

Beattie, S., Fakehy, M., \& Woodman, T. (2014). Examining the moderating effects of time on task and task complexity on the within person self-efficacy and performance relationship. Psychology of Sport and Exercise, 15, 605-610.

Beattie, S., Lief, D., Adamoulas, M., \& Oliver, E. (2011). Investigating the possible negative effects of self-efficacy upon golf putting performance. Psychology of Sport and Exercise, 12, $434-441$.

Beattie, S., Woodman, T., Fakehy, M., \& Dempsey, C. (2016). The role of performance feedback on the self-efficacy-performance relationship. Sport, Exercise, and Performance Psychology, 5, 1-13.

Beaumont, C., Maynard, I. W., \& Butt, J. (2015). Effective ways to develop and maintain robust sport-confidence: Strategies advocated by sport psychology consultants. Journal of Applied Sport Psychology, 27, 301-318.

Berlin, K., Williams, N., Parra, G. (2014). An Introduction to Latent Variable Mixture Modeling (Part 1): Overview and Cross-Sectional Latent Class and Latent Profile Analyses. Journal of Pediatric Psychology, 39(2), 174-187.

Brown, G., \& Potrac, P. (2009). 'You've not made the grade, son': de-selection and identity disruption in elite level youth football. Soccer \& Society, 2, 143-159.

Campbell, W. K., \& Sedikides, C. (1999). Self-threat magnifies the self-serving bias: A metaanalytic integration. Review of General Psychology, 3, 23 - 43.

Chase, M. A. (2001). Children's self-efficacy, motivational intentions, and attributions in physical education in sport. Research Quarterly for Exercise and Sport, 72, 47-54.

Christensen, M. K.., Laursen, D. N., \& Sørensen, J. K. (2011). Situated learning in youth elite football: a Danish case study among talented male under-18 football players. Physical Education and Sport Pedagogy, 16, $163-178$.

Cohen, J. (1988). Statistical power analysis for the behavioral sciences (2nd ed.). Hillsdale, 
Dunning, D. (2005). Self-insight: Roadblocks and detours on the path to knowing thyself. New York, NY: Psychology Press.

Ericsson, K. A., Krampe, R. T., \& Tesch-Römer, C. (1993). The role of deliberate practice in the acquisition of expert performance. Psychological Review, 100, 363-406.

Escarti, A., \& Guzman, J. F. (1999). Effects of feedback on self-efficacy, performance, and choice on an athletic task. Journal of applied Sport Psychology, 11, 8396.

Felson, R. B. (1981). Ambiguity and Bias in the self-concept. Social Psychology Quarterly, $44,64-69$.

Feltz, D.L., Short, S.E., \& Sullivan, P, S. (2007). Self-efficacy in sport: research and strategies for working with athletes, teams, and coaches. Champaign, IL: Human Kinetics.

Gibson, B., \& Sachau, D. A. (2000). Sandbagging as a self-presentational strategy: Claiming to be less than you are. Personality and Social Psychology Bulletin, 26, 56 - 70.

Halper, L., \& Vancouver, J. (2016). Self-efficacy's influence on persistence on a physical task: Moderating effect of performance feedback ambiguity. Psychology of Sport and Exercise, 22, $170-177$.

Hays, K., Thomas, O., Maynard. I., \& Bawden, M. (2009). The role of confidence in worldclass sport performance. Journal of Sport Sciences, 27, 1185-1199.

Heider, F. (1958). The psychology of interpersonal relations. New York, NY: Wiley.

Helsen, W., Van Winckel, J., \& Williams, A. M. (2005). The relative age effect in soccer across Europe. Journal of Sport Sciences, 23, 629-636.

Henson, J. M., Reise, S. P. \& Kim, K. H. (2007). Detecting mixtures from structural model fit statistics. Structural Equation Modeling, 14, 202-226.

Hofseth, E., Pedersen, J., Toering, T., \& Jordet, G. (In press). Shame-coping in professional soccer players: An exploratory interview analysis. International Journal of Sport Psychology.

Johnson, D. D. P., \& Fowler, J. H. (2011). The evolution of overconfidence. Nature, 477, $317-320$. 
Jones, G., Hanton, S., \& Swain, A. B. J. (1994). Intensity and interpretation of anxiety symptoms in elite and nonelite sports performers. Personality and Individual Differences, 17, $657-663$

Jordet, G. (2010). Choking under pressure as self-destructive behavior. In, A.R. Nicholls (Ed.), Coping in sport: theory, methods, and related constructs (pp. 239-259). New York, NY: Nova Science Publishers.

Jordet, G. (2009). When superstars flop: public status and "choking under pressure" in international soccer penalty shootouts. Journal of Applied Sport Psychology, 21, 125-130.

Kam, C., Morin. A. J. S., Meyer, J. P., \& Topolnytsky, L. (2013). Are commitment profiles stable and predictable? A latent transition analysis. Journal of Management. Advanced online publication.

Kantos, A. P. (2004). Perceived risk, risk taking, estimation of ability and injury among adolescent sport participants. Journal of Pediatric psychology, 29, 447-455.

Koehn, S. (2013). Effects of confidence and anxiety on flow state in competition. European Journal of Sport Science, 13, $543-548$.

Kruger, J., \& Dunning, D. (1999). Unskilled and unaware of it: How difficulties in recognizing one's own incompetence lead to inflated self-assessments. Journal of Personality and Social Psychology, 77, $1121-1134$

Mabe P. A., \& West, S. G. (1982). Validity of self-evaluation of ability: A review and metaanalysis. Journal of Applied Psychology, 67, 280 - 296.

Marsh, H. W., \& Perry, C. (2005). Self-concepts contributions to winning gold medals: Causal ordering of self-concept and elite swimming performance. Journal of Sport \& Exercise Psychology, 21, 71-91.

McGrath, D., \& Elison, J. (2014). Vertical Mind: Psychological approaches for optimal rock climbing. Boulder: Sharp End Publishing.

Moores, T. T., \& Chang, J. C. J. (2009). Self-efficacy, overconfidence, and the negative effect on subsequent performance: A field study. Information \& Management, 46, 69 - 76.

Muthén, L. K. and Muthén, B. O. (1998-2012). Mplus User's Guide. Seventh Edition. Los 
Angeles, CA: Muthén \& Muthén.

Nylund, K. L., Asparouhov, T. \& Muthén, B. (2007). Deciding on the number of classes in latent class analysis and growth mixture modeling: A Monte Carlo simulation study. Structural Equation Modeling, 14, 535-569.

Ommundsen, Y., Roberts, G. C., Lemyre, P.-N., \& Abrahamsen, F. (2007). What makes for a psychologically healthful versus risky soccer engagement? The motivational climate, psychological well-being and ill-being. In P. Heikinaro-Johansson, R. Telama, \& E McEvoy (Eds.), The role of physical education and sport in promoting physical activity and health (pp. 268 - 283). Jyväskylä, Finland: University of Jyväskylä, Sport Sciences.

Powers, W. T. (1973). Behavior: The control of perception. New York, NY: Hawthorne.

Prapavessis, H., Grove, J., \& Eklund, R. (2004). Self-presentational issues in competition and sport. Journal of Applied Sport Psychology, 16, 19-40.

Reinboth, M., \& Duda, J. L. (2004). The motivational climate, perceived ability, and athletes' psychological and physiological welfare of young athletes. Motivation and Emotion, 28, 297313.

Sarmento, H., Marcelino, R., Anguera, T. M., Campanico, J. Matos, N., \& Leitão, J. C. (2014). Match analysis in football: a systematic review. Journal of Sport sciences, 32, 18311843.

Scanlan, T. K., Carpenter, P. J., Lobel, M., \& Simons, J. P. (1993). Sources of enjoyment for youth sport athletes. Pediatric Exercise Science, 5, 275-285.

Smith, R. E., Smoll, F.L., Cumming, S. P., \& Grossbard, J. R. (2006). Measurement of multidimensional sport performance anxiety in children and adults: The Sport Anxiety Scale2. Journal of Sport \& Exercise Psychology, 29, 39 - 59.

Sterba, S. K., \& Bauer, D. J. (2010). Matching method with theory in person-oriented developmental psychopathology research. Development and Psychopathology, 22, 239.

Sitzmann, T., \& Yeo, G. (2013). A meta-analytical investigation of the within-person selfefficacy domain: Is self-efficacy a product of past performance or a driver of future performance? Personnel Psychology, 66, 531 - 568. 
Taylor, J., \& Cuave, K. (1994). The sophomore slump among professional baseball players: Real or imagined? International Journal of Sport Psychology, 25, 230 - 238.

Toering, T. (2011). Self-regulation of learning and the performance level of youth soccer players. Doctoral thesis. Groningen, Netherlands: University of Groningen.

Vancouver, J. B., \& Kendall, L. N. (2006). When self-efficacy negatively relates to motivation and performance in a learning context. Journal of Applied Psychology, 91, 1146 1153.

Vancouver J. B., Thompson, C. M., Tischner, E. C., \& Putka, D. J. (2002). Two studies examining the negative effect of self-efficacy on performance. Journal of Applied Psychology, 87, $506-16$.

Vancouver, J. B., \& Thompson, C. M., \& Williams, A. A. (2001). The changing signs in the relationships between self-efficacy, personal goals, and performance. Journal of Applied Psychology, 86, $605-20$.

Van Yperen, N. M. (2009). Why some make it and others do not: Identifying psychological factors that predict career success in professional adult soccer. The sport Psychologist, 23, $317-329$.

Van Yperen, N. M., \& Duda, J. L. (1999). Goal orientations, beliefs about success, and performance improvement among young elite Dutch soccer players. Scandinavian Journal of Medicine \& Science in Sports, 9, 358-364.

Vealey, R. S., Hayashi, S. W., Garner-Holman, M., \& Giacobbi, P. (1998). Sources of sportconfidence: Conceptualization and instrument development. Journal of Sport and Exercise Psychology, 20, $54-80$.

Wood, J., \& Feltz, D. (2013). Preparatory Efficacy Effects on Practice Effort and Performance. The Open Sports Science Journal, 6, 31 - 40. 
1 Table 1

2 Means, Standard Deviations, and Correlations among all Variables $(n=267)$.

\begin{tabular}{|c|c|c|c|c|c|c|c|c|c|}
\hline Variable & $M(S D)$ & 12 & 3 & 4 & 5 & 6 & 7 & 8 & \\
\hline 1. Age & $17.63(1.04)$ & .06 & $.16^{* *}$ & -.01 & -.11 & -.11 & $-.20 * *$ & -.02 & - \\
\hline 2. Player rating & $7.06(1.09)$ & . & $.26^{* *}$ & $.53 * *$ & $-.17 * *$ & $-.13 *$ & $-.27 * *$ & $-.17 * *$ & \\
\hline 3. Coach rating & $6.81(1.25)$ & & & $-.68 * *$ & $-.21 * *$ & $-.14 * *$ & $-.25 *$ & -.07 & \\
\hline 4. Discrepancy (pl. - co.) & $0.25(1.43)$ & & & . & .06 & .02 & .01 & -.07 & \\
\hline 5. Trait concentration disruption & $1.37(0.46)$ & & & & • & $-.37 * *$ & $.57 * *$ & $.45^{* *}$ & .2 \\
\hline 6. Trait somatic & $1.84(0.54)$ & & & & & . & $.56^{* *}$ & .04 & .2 \\
\hline 7. Trait worry & $1.95(0.70)$ & & & & & & . & $.22 * *$ & .2 \\
\hline 8. Self-handicapping & $1.62(0.65)$ & & & & & & & & \\
\hline 9. Sandbagging & $2.76(1.17)$ & & & & & & & & \\
\hline 10 Past national t. games & $2.81(7.62)$ & & & & & & & & \\
\hline 11. Future national t. games & $1.45(4.68)$ & & & & & & & & \\
\hline
\end{tabular}

$3 \quad$ Note: $*$ Significant at $p<.05, * *$ significant at $p<.01$

4

5

6

7

8

9

10

11

12

13

14 
1

2 Table 2

3 Means and Standard Deviations among All Variables across Classes

\begin{tabular}{lccc}
\hline & \multicolumn{3}{c}{ Class } \\
\cline { 2 - 4 } Variable & 1 & \multicolumn{1}{c}{2} & \multicolumn{1}{c}{3} \\
\hline Age & $17.35(1.00)$ & $17.69(1.03)$ & $1.80(1.04)$ \\
Player rating & $6,20(0.94)$ & $7.60(0.85)$ & $7.25(0.98)$ \\
Coach rating & $5.55(0.79)$ & $6.48(0.60)$ & $8.09(0.63)$ \\
Discrepancy (pl. - co.) & $.66(1.38)$ & $1.12(1.07)$ & $-0.85(0.97)$ \\
Trait concentration disruption & $1.55(0.54)$ & $1.35(0.43)$ & $1.27(0.37)$ \\
Trait somatic & $1.98(0.61)$ & $1.76(0.54)$ & $1.79(0.45)$ \\
Trait worry & $2.25(0.75)$ & $1.84(0.69)$ & $1.82(0.62)$ \\
Self-handicapping & $1.66(0.55)$ & $1.59(0.64)$ & $1.61(0.73)$ \\
Sandbagging & $2.82(1.24)$ & $2.63(1.26)$ & $2,59(1.13)$ \\
Past national t. games & $0.12(0.83)$ & $0.34(1.54)$ & $3.47(7.05)$ \\
Future national t. games & $1.05(3.94)$ & $1.74(6.12)$ & $5.11(10.07)$
\end{tabular}




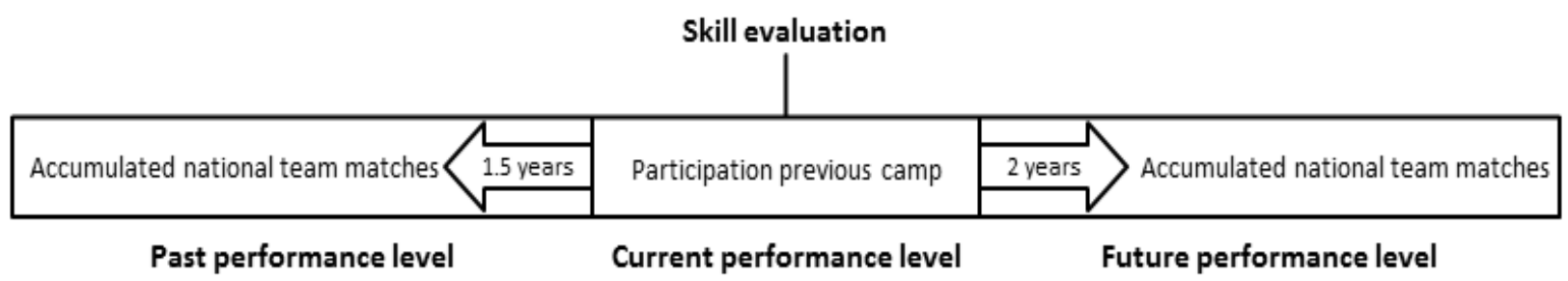

1

2 Figure 1. Illustration of reserch design.

3

4

5

6

7

8

9 
Entire sample $(N=267)$
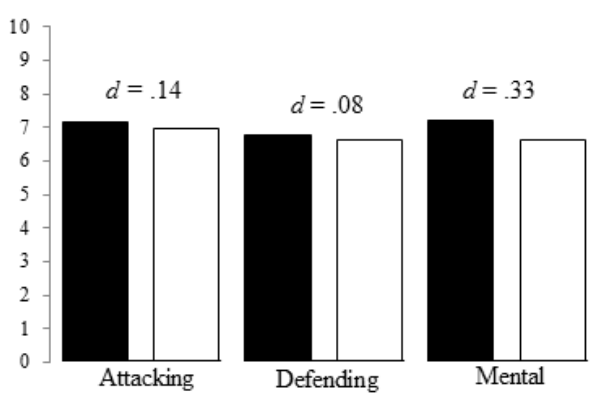

Profile $2(n=90)$
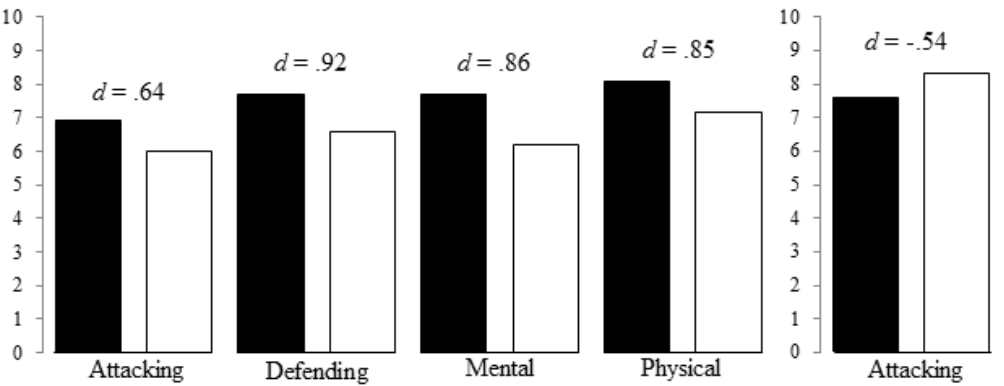

$d=-.68$

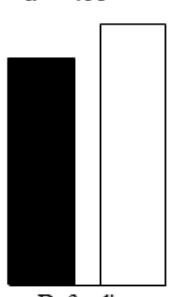

Defending

Profile $1(n=77)$

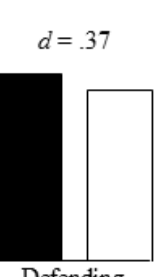

Profile $3(n=100)$

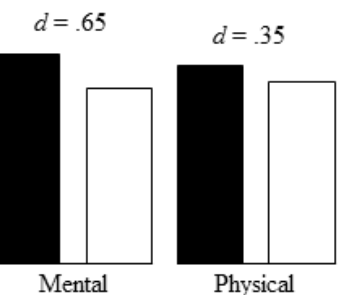

$d=-.38$

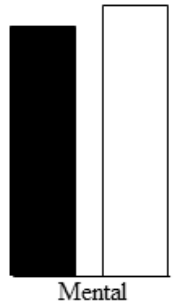

$d=-.89$

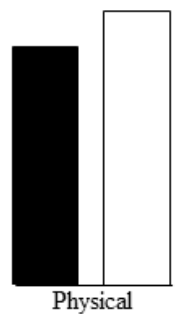

2 Figure 2. Description of the profiles; black bars represent players' ratings of their own skill

3 level, and white bars represent coaches' ratings of players' skill level. $d=$ cohen's estimated 4 effect size between players' and coaches' ratings.

5

6

7 